Jurnal Kesehatan 14 (2) 2021, 137-141

\title{
Perbandingan Minuman Jus Belimbing Dan Jus Wortel Terhadap Penurunan Tekanan Darah Penderita Hipertensi Pada Lansia Di Kelurahan Rancagede Tahun 2020
}

\author{
Solihati ${ }^{1}$, Lastri Mei Winarni ${ }^{2}$, Siti Sumaedah ${ }^{3}$ \\ STIKes Yatsi, Jl. Aria Santika No.40A Margasari Karawaci Tangerang Banten 15113 \\ Email : solihati@stikesyatsi.ac.id, lastri@stikesyatsi.ac.id, sitisumaedah@gmail.com
}

Tanggal Submisi: 23 Januari 2021; Tanggal Penerimaan: 6 Juli 2021

\begin{abstract}
Abstrak
Pendahuluan, hipertensi menjadi urutan keenam dalam sepuluh penyakit tidak menular di Indonesia . Tujuan penelitian ini untuk mengetahui perbandingan minuman jus belimbing dan jus wortel terhadap tingkat perubahan tekanan darah penderita hipertensi pada lansia. Metode penelitian menggunakan kuasi eksperimen dengan pendekatan One Group pretest and post test untuk membandingkan hasil intervensi pemberian minuman jus belimbing dan jus wortel. Total sampel yang diambil adalah 30 responden dengan kelompok jus belimbing 15 responden dan kelompok jus wortel 15 responden, teknik pengambilan sampel menggunakan incidental sampling. Intervensi dilaksanakan dengan memberikan jus belimbing dan jus wortel kepada masing-masing kelompok selama 5 hari dalam 5 minggu. Tekanan darah di ukur menggunakan Sphygmomanometer dan analisis perbedaan menggunakan uji Mann-Whitney. Kesimpulan Pemberian jus belimbing menurunkan tekanan sistolik sekitar $44 \mathrm{mmHg}$ dan menurunkan tekanan diastolik sekitar $22 \mathrm{mmHg}$, sedangkan pemberian jus wortel menurunkan tekanan sistolik dengan rata-rata $33,34 \mathrm{mmHg}$ dan menurunkan tekanan diastolik rata-rata $7.34 \mathrm{mmHg}$. Hasil uji Mann-Whitney diketahui $p$ value 0.000 untuk pemberian jus belimbing dan 0.002 untuk pemberian jus wortel
\end{abstract}

Kata kunci : Hipertensi, Jus belimbing, Jus wortel, Lansia, Tekanan Darah

\begin{abstract}
Introduction, hypertension ranks sixth in ten non-communicable diseases in Indonesia. The purpose of this study was to determine the ratio of star fruit juice and carrot juice drinks to the level of changes in blood pressure in elderly people with hypertension. The research method used a quasi-experimental with the One Group pretest and post test approach to compare the results of the intervention giving star fruit juice and carrot juice drinks. The total sample taken was 30 respondents with the star fruit juice group 15 respondents and the carrot juice group 15 respondents, the sampling technique used incidental sampling. The intervention was carried out by giving star fruit juice and carrot juice to each group for 5 days in 5 weeks. Blood pressure was measured using a Sphygmomanometer and analysis of differences using the Mann-Whitney test. Conclusion The administration of starfruit juice decreased systolic pressure by about $44 \mathrm{mmHg}$ and decreased diastolic pressure by about $22 \mathrm{mmHg}$, while giving carrot juice decreased systolic pressure by an average of $33.34 \mathrm{mmHg}$ and decreased diastolic pressure by an average of $7.34 \mathrm{mmHg}$. The results of the Mann-Whitney test showed that the $p$ value was 0.000 for star fruit juice and 0.002 for giving carrot juice
\end{abstract}

Keywords: hypertension, star fruit juice, carrot juice, elderly, blood pressure

ISSN 1979-7621 (Print). ISSN 2620-7761 (Online)

DOI 10.23917/jk.v14i2.13476

\section{PENDAHULUAN}

Hipertensi menjadi penyebab utama kematian di Indonesia, saat ini hipertensi berada pada peringkat ke-6 dari 10 penyakit tidak menular kronis. Seseorang didiagnosis darah tinggi jika memiliki tekanan darah 
sistolik $\geq 140 \mathrm{mmHg}$ dan diastolik $\geq 90$ mmHg. World Health Organization (WHO) memperkirakan bahwa pada tahun 2020, $73 \%$ penyakit tidak menular (PTM) akan meyebabkan mortalitas dan $60 \%$ morbiditas di dunia. Penyakit hipertensi kronis dapat berkambang menjadi penyakit kardiovaskuler, stroke, gagal ginjal serta gangguan pada mata. Hasil penelitian Setyaningsih tahun 2014 menjelaskan bahwa hipertensi yang tidak terkontrol dapat menjadi 7 kali menyebabkab stroke dan 6 kali dapat mengakibatkan kegagalan jantung kongesti dan 3 kali dapat mengakibatkan serangan jantung [1].

Angka penderita hipertensi di Indonesia cenderung mengalami peningkatan dalam 10 tahun terakhir. Prevalensi hipertensi di Indonesia pada tahun 2013, paling tinggi terjadi pada kelompok usia 3544 tahun yaitu sekitar $24.8 \%$ dan akan meningkat seiring bertambahnya [2]. Kelompok orang lanjut usia (lansia) merupakan kelompok yang rentan terkena hipertensi. Hipertensi dapat menjadi salah satu proses dari penuaan, namun tetap harus dikelola dengan baik agar dapat meminimalisir timbulnya penyakit lain yang lebih serius, seperti stroke, jantung dan gagal ginjal. Pengaturan hipertensi pada lansia dapat membantu menurunkan tingkat morbiditas dan mortalitas akibat penyakitpenyakit kardiovaskuler. Hal ini berarti bahwa risiko penyakit akibat hipertensi dapat dicegah dengan mengelola tekanan darah pada penderita hipertensi agar selalu terkontrol dan normal [1].

Berdasarkan studi pendahuluan pada tanggal 07 Desember 2019 di Puskesmas Gunung Kaler didapatkan data bahwa jumlah lansia adalah 4282 orang, lansia yang menderita hipertensi pada bulan November 2019 adalah sekitar 433 orang. Dilakukan pemeriksaan tekanan darah pada 30 lansia $100 \%$ mengalami hipertensi, para lansia yang hipertensi ini diberikan obat anti hipertensi dari Puskesmas. Peneliti ingin mengembangkan pengobatan tradisonal menggunakan bahan-bahan yang ada disekitar lingkungan masyarakat serta mudah mendapatkannya. Salah satunya adalah buah belimbing dan sayuran wortel yang sejak lama telah dipercaya masyarakat dapat mengatasi hipertensi. Bagi para lansia cara mengkonsumi buah dan sayuran lebih mudah jika dibuat dalam minuman jus, karena cepat diserap oleh tubuh dan segera di distribusikan ke seluruh tubuh.

Belimbing memiliki rasa yang manis dan segar selain itu juga mengandung banyak vitamin seperti vitamin A, B1, C, dan lemak tak jenuh. Salah satu penelitian Novia 2018 di Puskesmas Andalas menyatakan bahwa responden yang mengkonsumsi jus belimbing dapat menurunkan darah sistolik dibandingkan sebelum mengkonsumsi jus belimbing [3]. Penelitian Suwito tahun 2019 di Puskesmas Koto juga menjelaskan bahwa pemberian jus belimbing lebih efektif dibandingkan pemberian jus mentimun sebanyak 2 kali sehari selama 12 hari dalam menurunkan tekanan darah sistolik [4]. Sedangkan penelitian Mariyati 2017 di Panti Wredha Harapan Ibu Semarang menjelaskan bahwa lansia yang mengkonsumsi jus belimbing mengalami penurunan tekanan darah sistolik dan diastoliknya [5].

Jus wortel baik dikonsumsi untuk penderita hipertensi karena dapat menurunkan berat badan yang menjadi salah satu pemicu penyakit hipertensi. Agar dapat hasil yang maksimal jus wortel ini dapat dikonsumsi satu gelas setiap hari. Dalam satu gelas jus wortel mengandung kalsium sebanyak $27 \mathrm{mg}$, Ferrous sulfat sebanyak 0,5 mg, Sodium sebanyak $34 \mathrm{mg}$, Fosfor sebanyak $26 \mathrm{mg}$, Pottassium sebanyak 246 $\mathrm{mg}$, vitamin $\mathrm{C}$ sebanyak $6 \mathrm{mg}$, vitamin A sebanyak 7,93 IU, dan vitamin B kompleks. Berdasarkan penelitian Laili 2016 di Kediri menyampaikan bahwa pemberian jus belimbing pada lansia yang menopause di Posyandu mengalami penurunan hingga 51 mmHg pada tekanan sistoliknya [6]. Hasil penelitian tersebut didukung dengan penelitian Laila 2019 di Puskesmas Tapus Pasaman Timur yaitu dengan memberikan jus wortel pada lansia usia 50-70 tahun sebanyak $200 \mathrm{ml}$ satu kali dalam sehari selama tujuh hari akan mengalami penurunan 
tekanan sistolik sekitar $25 \mathrm{mmHg}$ [7]. Hasil penelitian tersebut juga didukung oleh Wijaya 2018 yang memberikan 100 gram wortel yang dijus dan dicampur dengan madu selama tujuh hari kepada lansia dapat membantu menurunkan tekanan sistolik ratarata $15,16 \mathrm{mmHg}$ dan tekanan diastolik turun rata-rata $10,97 \mathrm{mmHg}[8]$.

Berdasarkan latar belakang diatas peneliti tertarik untuk melihat perbedaan penurunan tekanan darah pada lansia yang diberikan jus belimbing dan jus wortel, sehingga tujuan dari penelitian ini adalah untuk mengetahui perbandingan minuman jus belimbing dan jus wortel terhadap tingkat perubahan tekanan darah penderita hipertensi pada lansia.

\section{METODOLOGI PENELITIAN}

Desain penelitian yang digunakan adalah kuasi eksperimen dengan rancangan penelitian Non Equivalent (pretest and post test) Control Group Desain. Populasi penelitian ini adalah lansia yang mengalami hipertensi di Kelurahan Rancagede. Sampel penelitian ini berjumlah 30 responden yang terbagi menjadi dua kelompok, yaitu kelompok jus belimbing dan kelompok jus wortel masing-masing sejumlah 15 responden per kelompok. Teknik yang digunakan dalam mengambil sampel adalah insidental sampling. Kriteria inklusi responden adalah lansia yang bersedia untuk tidak minum obat antihipertensi selama mendapatkan jus belimbing dan jus Wortel.

Pengumpulan data pada penelitian ini menggunakan lembar observasi pencatatan tekanan darah setiap hari selama lima minggu. Pengukuran tekanan darah menggunakan tensimeter lapangan. Pemberian jus belimbing dan jus wortel sebanyak $200 \mathrm{ml} /$ hari dilakukan pada pagi hari setelah makan pada lima hari kerja selama lima minggu. Selanjutnya dilakukan pengukuran tekanan darah (post test) setelah minggu kelima. Analisis data menggunakan analisis univariat dan uji Mann-Whitney untuk melihat perbandingan rerata tekanan sistolik dan diastolik. Penelitian ini telah lulus uji etik dengan nomor surat 027/LPPMSTIKES YATSI/V/2020

\section{HASIL DAN PEMBAHASAN}

Hasil dari penelitian ini adalah sebagai berikut :

\section{Tabel 1.1 Distribusi nilai rerata tekanan darah sebelum-sesudah diberikan Jus Belimbing Pada Lansia Di Kelurahan Rancagede Tahun 2020}

\begin{tabular}{|c|c|c|c|c|c|c|c|}
\hline & \multicolumn{7}{|c|}{ Tekanan Darah Pre-Post Pemberian Jus Belimbing } \\
\hline & $\mathbf{N}$ & Mean & Median & Modus & Std. & $\begin{array}{l}\text { Min- } \\
\text { Max }\end{array}$ & $\begin{array}{l}\text { Nilai } p \\
\text { Value }\end{array}$ \\
\hline $\begin{array}{c}\text { Pre } \\
\text { Sistolik }\end{array}$ & 15 & 170,67 & 180,00 & 180 & 12,228 & $\begin{array}{l}150- \\
180\end{array}$ & 0,000 \\
\hline $\begin{array}{c}\text { Post } \\
\text { Sistolik }\end{array}$ & 15 & 126,67 & 130,00 & 120 & 7,237 & $\begin{array}{l}120- \\
140\end{array}$ & \\
\hline $\begin{array}{c}\text { Pre } \\
\text { Diastolik }\end{array}$ & 15 & 96,00 & 100,00 & 100 & 5,071 & $\begin{array}{l}90- \\
100\end{array}$ & 0,000 \\
\hline $\begin{array}{c}\text { Post } \\
\text { Diastolik }\end{array}$ & 15 & 74,00 & 70,00 & 70 & 7,368 & $70-90$ & \\
\hline
\end{tabular}

Berdasarkan tabel 1.1 diketahui bahwa rata-rata pre test sistolik 170,67, dengan nilai tengah 180,00, standar deviasi 12,228. Rata-rat post test sistolik belimbing 126,67, dengan nilai tengah 130,00, standar deviasi 7,237. Rata-rata pre test diastolik belimbing 96,00, dengan nilai tengah 100,00, standar deviasi 5,071. Rata-rata post test diastolik belimbing 74,00, dengan nilai tengah 70,00, standar deviasi 7,368. Pemberian jus belimbing mampu menurunkan tekanan sistolik rata-rata 44 $\mathrm{mmHg}$, dan menurunkan tekanan diastolik rata-rata sekitar $22 \mathrm{mmHg}$.

Hasil penelitian ini sejalan dengan penelitian Novia 2018 di Puskesmas Andalas menyatakan bahwa terjadi penurunan darah sistolik pada responden yang mengkonsumsi jus belimbing dibandingkan dengan tekanan darah sistolik sebelum mengkonsumsi jus belimbing [3]. Penelitian Suwito tahun 2019 di Puskesmas Koto juga menjelaskan bahwa pemberian jus belimbing lebih memberikan efektifitas dibandingkan pemberian jus mentimun, dengan frekuensi sebanyak 2 kali sehari selama 12 hari dalam menurunkan 
tekanan darah sistolik [4]. Sedangkan penelitian Mariyati 2017 di Panti Wredha Harapan Ibu Semarang menjelaskan bahwa lansia yang mengkonsumsi jus belimbing dapat membantu menurunkan tekanan darah sistolik dan diastoliknya [5].

Tabel 1.2 Distribusi nilai rerata tekanan darah sebelum-sesudah diberikan Jus Wortel Pada Lansia Di Kelurahan Rancagede Tahun 2020

\begin{tabular}{|c|c|c|c|c|c|c|c|}
\hline \multicolumn{8}{|c|}{ Tekanan Darah Pre-Post Pemberian Jus Wortel } \\
\hline & $\mathbf{N}$ & Mean & Median & $\begin{array}{l}\text { Mo } \\
\text { dus }\end{array}$ & Std. & $\begin{array}{l}\text { Min- } \\
\text { Max }\end{array}$ & $\begin{array}{c}\text { Nilai } \\
\mathbf{P} \\
\text { Value }\end{array}$ \\
\hline $\begin{array}{c}\text { Pre } \\
\text { Sistolik }\end{array}$ & 15 & 170,67 & 170,00 & 170 & 7,988 & $\begin{array}{l}160- \\
180\end{array}$ & 0,002 \\
\hline $\begin{array}{c}\text { Post } \\
\text { Sistolik }\end{array}$ & 15 & 137,33 & 140,00 & 140 & 15,796 & $\begin{array}{l}120- \\
170\end{array}$ & \\
\hline $\begin{array}{c}\text { Pre } \\
\text { Diastolik }\end{array}$ & 15 & 100,67 & 100,00 & 100 & 5,936 & $\begin{array}{c}110- \\
90\end{array}$ & 0,002 \\
\hline $\begin{array}{c}\text { Post } \\
\text { Diastolik }\end{array}$ & 15 & 93,33 & 90,00 & 90 & 4,880 & $\begin{array}{c}100- \\
90\end{array}$ & \\
\hline
\end{tabular}

Berdasarkan tabel 1.1 diketahui bahwa rata-rata pre test sistolik 170,67, dengan nilai tengah 170,00 , standar deviasi 7,988. Rata-rat post test sistolik belimbing 137,33, dengan nilai tengah 140,00, standar deviasi 15,796 . Rata-rata pre test diastolik belimbing 100,67, dengan nilai tengah 100,00, standar deviasi 5,936. Rata-rata post test diastolik belimbing 93,33, dengan nilai tengah 90,00, standar deviasi 4,880. Pemberian jus belimbing mampu menurunkan tekanan sistolik rata-rata 33,34 $\mathrm{mmHg}$, dan menurunkan tekanan diastolik rata-rata sekitar 7,34 $\mathrm{mmHg}$

Hasil Penelitian ini didukung dengan penelitian Laili 2016 di Kediri menyampaikan bahwa pemberian jus belimbing pada lansia yang menopause di
Posyandu mengalami penurunan hingga 51 mmHg pada tekanan sistoliknya [6]. Hasil penelitian tersebut didukung dengan penelitian Laila 2019 di Puskesmas Tapus Pasaman Timur yaitu dengan memberikan jus wortel pada lansia usia 50-70 tahun sebanyak $200 \mathrm{ml}$ satu kali dalam sehari selama tujuh hari akan mengalami penurunan tekanan sistolik sekitar $25 \mathrm{mmHg}$ [7]. Hasil penelitian tersebut juga didukung oleh Wijaya 2018 yang memberikan 100 gram wortel yang dijus dan dicampur dengan madu selama tujuh hari kepada lansia dapat membantu menurunkan tekanan sistolik ratarata $15,16 \mathrm{mmHg}$ dan tekanan diastolik turun rata-rata $10,97 \mathrm{mmHg}$ [8]. Jus wortel baik dikonsumsi untuk penderita hipertensi karena dapat menurunkan berat badan yang menjadi salah satu pemicu penyakit hipertensi. Agar dapat hasil yang maksimal jus wortel ini dapat dikonsumsi satu gelas setiap hari. Dalam satu gelas jus wortel mengandung kalsium sebanyak $27 \mathrm{mg}$ kalsium, zat besi sebanyak 0,5 mg, Sodium sebanyak $34 \mathrm{mg}$, Fosfor $26 \mathrm{mg}$, Pottasium sebanyak $246 \mathrm{mg}$, vitamin C sebanyak $6 \mathrm{mg}$, vitamin A sebanyak 7,93 IU, dan vitamin B kompleks.

\section{KESIMPULAN}

Terdapat perbedaan rerata penurunan tekanan sistolik dan tekanan diastolik dalam pemberian jus belimbing dan jus wortel. Pemberian jus belimbing menurunkan tekanan sistolik sekitar $44 \mathrm{mmHg}$ dan menurunkan tekanan diastolik sekitar 22 mmHg, sedangkan pemberian jus wortel menurunkan tekanan sistolik dengan rata-rata 33,34 $\mathrm{mmHg}$ dan menurunkan tekanan diastolik rata-rata $7.34 \mathrm{mmHg}$. Hasil uji Mann-Whitney diketahui $\mathrm{p}$ value 0.000 untuk pemberian jus belimbing dan 0.002 untuk pemberian jus wortel.

\section{DAFTAR PUSTAKA}

[1] R. D. Setyaningsih, P. Dewi, and M. Suandika, "Studi Prevalensi Dan Kajian Faktor Risiko Hipertensi Padalansia Di Desa Tambaksari - Banyumas,” Pros. Semin. Nas. Int., 2014.

[2] S. Tirtasari and N. Kodim, "Prevalensi dan Karakteristik Hipertensi Pada Usia Dewasa Muda di Indonesia," Tarumanagara Med. J., vol. 1, no. 2, pp. 395-402, 2019.

[3] V. R. Novia, Sujarwo, and M. U. Wulandari, "Pengaruh Pemberian Jus Belimbing 
(Averrhoe Carambola Linn) Terhadap Penurunan Tekanan Darah Pada Penderita Hipertensi di Wilayah Kerja Puskesmas Andalas Tahun 2018," J. Kesehat. Saintika Meditory, vol. 1, no. 1, pp. 64-69, 2018.

[4] A. Suwito and M. Sari, "Efektifitas Pemberian Jus Belimbing Manis dan Mentimun Terhadap Tekanan Darah Penderita Hipertensi," J. Kesehat., vol. 7, no. 2, pp. 150155, 2019, doi: 10.24252/kesehatan.v7i2.54.

[5] M. Mariyati and W. Wahyuningsih, "Keefektifan Pemberian Jus Belimbing Pada Lansia Dalam Menurunkan Tekanan Darah Di Panti Wredha Harapan Ibu Semarang," J. Manaj. Asuhan Keperawatan, vol. 1, no. 1, pp. 44-54, 2017, doi: 10.33655/mak.v1i1.8.

[6] F. Laili, G. P. Y, and I. Fitri, "Pengaruh Pemberian Jus Wortel terhadap Perubahan Tekanan Darah pada Menopause Penderita Hipertensi di Posyandu Lansia Puskesmas Sukorame Kota Kediri Tahun 2016," 2016.

[7] W. Laila, N. Nurhamidah, and L. Santika, "Pengaruh Pemberian Jus Wortel Terhadap Penurunan Tekanan Darah Pada Penderita Hipertensi Derajat 1 Lansia Umur 50-70 Tahun di Wilayah Kerja Puskesmas Tapus Kabupaten Pasaman Timur," Pros. Semin. Kesehat. Perintis, vol. 2, no. 1, pp. 129-132, 2019.

[8] I. P. A. Wijaya, I. M. D. Pradnya, and I. G. A. W. P. Dita, "Pengaruh Kombinasi Jus Wordu (Wortel dan Madu) Terhadap Penurunan Tekanan darah pada Lansia," Caring, vol. 2, no. 2, pp. 58-62, 2018. 